\title{
Avaliação da atenção humanizada ao abortamento: um estudo de avaliabilidade
}

\section{1 Bianca Nunes Guedes do Amaral Rocha, ${ }^{2}$ Severina Alice da Costa Uchoa I}

Resumo: No Brasil, estima-se que ocorram anualmente 1.443.350 abortos, que levam milhares de mulheres, com abortamento incompleto, a buscar atendimento nos serviços públicos de saúde. Em 2005, o Ministério da Saúde publicou a Norma Técnica de Atenção Humanizada ao Abortamento como resposta a este desafio. Este artigo objetiva discutir se o conjunto de intervençôes da norma constitui um programa avaliável e propor um modelo de avaliação. A pesquisa, realizada em 2010, caracteriza-se como estudo de avaliabilidade. Utilizaram-se as técnicas de análise documental e entrevista com informantes-chave. Para validação dos indicadores, foi aplicada a técnica do grupo nominal. Como resultados, foram elaborados e pactuados o modelo lógico, a matriz dos indicadores e as perguntas avaliativas que traduzem os pilares da atenção: acolhimento, atenção clínica com qualidade técnica, ética e legal, planejamento reprodutivo, integração com a rede de saúde e com coletivos de mulheres. Conclui-se que a atenção humanizada ao abortamento é um programa avaliável com elaboração de um modelo de avaliação no momento oportuno. A pré-avaliação demonstrou ser adequada e mais bem compreendida pelo gestor e profissionais. Houve concordância quanto à clareza e pertinência das metas, necessidades de recursos e ações, questões éticas para orientar mudanças. O estudo aumentou o conhecimento dos atores envolvidos com participação decisiva da direção clínica. Para avaliações subsequentes, o estudo recomenda o foco em estrutura e processos dos cinco componentes do programa com priorização dos aspectos subjetivos da humanização, infraestrutura, além da prevalência do aborto no serviço público de saúde.

> Palavras-chave: avaliação; abortamento; humanização; saúde da mulher.

\footnotetext{
1 Departamento de Saúde

Coletiva da UFRN e doutoranda do Programa de Pós-Graduação em Saúde Coletiva formada em Fisioterapia pela UFPB. Endereço eletrônico: bianca.guedes@ gmail.com

${ }^{2}$ Médica, docente do Departamento de Saúde Coletiva da Universidade Federal do Rio Grande do Norte (UFRN). Endereço eletrônico: aliuchoa@hotmail.com
} 
A Organização Pan-americana da Saúde considera a mortalidade materna como um indicador importante da qualidade da atenção prestada às mulheres e, portanto, das condições de vida de uma população. Neste contexto, por sua morbimortalidade, o abortamento é considerado um grave problema de saúde pública, sobretudo nos países em desenvolvimento, e adquiriu maior visibilidade com a ampliação da discussão acerca do empoderamento de ações no campo da saúde da mulher (OPAS, 2005).

No mundo, ocorrem 529 mil mortes maternas por ano, das quais as complicações do abortamento respondem por uma parcela de aproximadamente 13\%. De 210 milhões de gestaçôes que ocorrem a cada ano, metade delas é indesejada. Calcula-se que uma a cada nove dessas mulheres recorre à interrupção, o que resulta em cerca de 46 milhôes (22\%) de abortamentos induzidos. Destes, 20 milhões são realizados em condiçōes inseguras. A América Latina registra $17 \%$ dos abortamentos clandestinos, perdendo apenas para a África, que permeia em torno de 58\% (OMS, 2004; GRIMES et al., 2006).

No Brasil, segundo dados do Ministério da Saúde, estima-se que 31\% das gestações terminem em abortamento, correspondendo a 1.443 .350 abortamentos anuais, o que resulta em uma taxa de 3,7 abortamentos/100 mulheres de 15 a 49 anos. Este valor é superior aos encontrados em países da Europa ocidental, onde a prática é legal e acessível e está associada à grande disponibilidade de meios de planejamento familiar (BRASIL, 2005; 2010).

Através de uma série histórica de hospitalizações de 1992 a 2005 na rede pública, registradas no Sistema de Informação Hospitalar do Sistema Único de Saúde (SIH-SUS), foram encontrados 1.054.242 internamentos por aborto, equivalendo a uma taxa média de 2,07 abortos por 100 mulheres entre 15 a 49 anos de idade em 2005. O estudo constatou, em todas as regiōes e para todos os grupos etários, uma tendência de redução das internações por abortamento até 1996, com estabilização do número de casos até 2005. Entretanto, o risco do aborto inseguro não se distribui igualmente entre a população feminina em idade fértil no país, e observou-se maior incidência nas regiōes Norte e Nordeste (ADESSE; MONTEIRO; LEVIN, 2008). 
Resultados da Pesquisa Nacional de Aborto (PNA), através de levantamento por amostragem aleatória de domicílios, com mulheres urbanas de idade entre 1839 anos, demonstraram que o número de mulheres que fizeram aborto aumenta com a idade, variando em uma proporção de $6 \%$ para mulheres com idades entre 18 e 19 anos a $22 \%$ entre mulheres de 35 a 39 anos (DINIZ, 2010).

O cenário político e social brasileiro apresenta mudanças e permanências quanto ao aborto, persistindo a inflexibilidade da legalização punitiva em vigor e a influência de grupos religiosos contrários à descriminalização da prática. $\mathrm{O}$ tema adquiriu maior visibilidade social nas últimas décadas e foi objeto de luta por direitos reprodutivos nos movimentos feministas. Atualmente, ganhou destaque com a mais recente decisão do Supremo Tribunal Federal (STF), quando, em abril de 2012, os ministros entenderam que não é crime interromper a gravidez de fetos anencéfalos (MENEZES; AQUINO, 2009; STF, 2012).

Mesmo nos casos em que as mulheres tenham o direito de fazer um abortamento legal, por correrem risco de morte, não encontram serviços seguros disponíveis, por razões diversas, como a falta de profissionais treinados ou a concentração destes em áreas urbanas e a atitude negativa dos profissionais (MEDEIROS et al., 2012). Ressaltam-se, também, o uso de métodos inapropriados ou obsoletos para indução do abortamento, a falta de conhecimento da lei de sua aplicação pelos serviços de saúde, as exigências reguladoras complexas ou a falta de recursos. Fatores sociais mais amplos e as políticas de saúde também influenciam na disponibilidade de serviços, tais como normas ou requisitos legais, falta de informação do público sobre a lei e sobre os direitos das mulheres, bem como o desconhecimento de que existem estabelecimentos que realizam o abortamento e da necessidade de solicitar o abortamento nas primeiras semanas de gravidez, atitude dos familiares, estigma e medo da perda da privacidade e confidencialidade e a percepção sobre a qualidade do atendimento disponível (OMS, 2004).

Entre os procedimentos obstétricos mais realizados nas unidades de internação da rede pública de serviços de saúde dos brasileiros, a curetagem pós-abortamento ocupa a terceira posição. Aspectos culturais, religiosos, legais e morais inibem as mulheres a declarar seus abortamentos, dificultando o cálculo da sua magnitude (BRASIL, 2010). 
Em 1984, preocupado com a morbimortalidde e atendendo às pressōes dos movimentos feministas, o Ministério da Saúde elaborou o Programa de Assistência Integral à Saúde da Mulher (PAISM). O PAISM incorporou, como princípios e diretrizes, as propostas de descentralização, hierarquização e regionalização dos serviços, bem como a integralidade e a equidade da atenção, num período em que, paralelamente, no âmbito do Movimento Sanitário, se concebia o arcabouço conceitual que embasaria a formulação do SUS (OSIS, 1998).

Como signatário da Conferência Internacional sobre População e Desenvolvimento (CIPD), realizada no Cairo em 1994, e da $4^{a}$ Conferência Mundial sobre a Mulher, ocorrida em Beijing em 1995, o Brasil assumiu o compromisso dos direitos sexuais e reprodutivos das mulheres como uma questão de direitos humanos e recomendou uma atenção de qualidade para todas as pessoas, mulheres e homens, de modo que possam exercer tais direitos (BRASIL, 2010).

Em 2005, o governo brasileiro criou a Norma Técnica para Atenção Humanizada ao Abortamento, como um guia para uma atenção pós-abortamento de qualidade, além de ser um referencial ético e legal para os serviços e profissionais na assistência à saúde das mulheres (BRASIL, 2005; BRASIL, 2010). A norma técnica propóe estratégias de expansão do acesso à atenção de qualidade ao pós-abortamento, envolvendo atenção clínica adequada, seguindo princípios éticos, legais e bioéticos, acolhimento e orientação para atender às necessidades da mulher, sejam elas de caráter emocional, social ou físico, prática integrada com outros serviços de atenção à saúde e de inclusão social da mulher, garantia do planejamento reprodutivo no pós-abortamento e parceria entre comunidade e profissionais de saúde para garantir um serviço de qualidade (BRASIL, 2005; 2010).

Para o Ministério da Saúde, as pesquisas em saúde da mulher são fundamentais para monitorar e avaliar a implementação e o desenvolvimento das políticas públicas, direcionadas à saúde das mulheres, bem como para subsidiar sua elaboração ou redirecioná-las, tornando-as cada vez mais adequadas às necessidades do SUS (BRASIL, 2005).

Menezes e Aquino (2009), em extensa revisão na área de Saúde Coletiva, mostram que a maioria das investigações enfoca a descrição do perfil das mulheres que informaram provocar aborto, os métodos utilizados, as razões alegadas para fazê-lo, o nível de informação, a utilização de contraceptivos e as 
consequências imediatas para a saúde física. Ainda que todas as abordagens sejam importantes, suas análises são limitadas a algumas variáveis e restringem-se a um enfoque transversal do problema. Não foram frequentes, portanto, estudos que demonstrassem um modelo explicativo capaz de articular essas variáveis para se apreender a complexidade e a dimensão deste fenômeno.

Estudos realizados em hospitais no país demonstram a relevância crescente da abordagem referente ao aborto sobre diversos aspectos, como: características qualitativas da relação interpessoal entre os profissionais de saúde e a mulher com abortamento incompleto durante o atendimento em maternidadeescola do Rio Grande do Norte (MOTTA, 2005); análise e comparação do conhecimento e opiniōes de estudantes dos cursos de Direito e Medicina sobre a questão do aborto no Brasil (MEDEIROS et al., 2012); frequência de exposição ao misoprostol e o espectro de malformações associadas (OPALEYE et al.; 2010); e a influência da percepção dos profissionais quanto ao aborto provocado na atenção à saúde da mulher (BENUTE et al., 2012). Entretanto, ainda são poucas as investigações que avaliam especificamente a qualidade da atenção ao abortamento dentro dos marcos legais, éticos e políticos da Norma da Atenção Humanizada ao Abortamento.

Ao trabalhar com avaliação de políticas de humanização, é importante destacar que seus indicadores devem não somente dimensionar mudanças nos quadros de saúde-doença, mas também questões envolvidas no próprio processo de trabalho em saúde, por estar intrinsecamente atrelada aos processos de planejamento e de gestão, vislumbrando a perspectiva interdisciplinar da avaliação e valendo-se, para tanto, da adoção de diferentes metodologias avaliativas (SANTOS FILHO, 2007). Nesta perspectiva, considerando o escopo da avaliação da qualidade de políticas e programas, é recomendável realizar um estudo de avaliabilidade ou pré-avaliação.

De acordo com Trevisan e Huang (2003), um estudo de avaliabilidade é o primeiro passo para avaliar programas, aumentando a probabilidade de fornecer avaliações oportunas, relevantes e de interesse para as tomadas de decisão. Permite, assim, que a avaliação tenha a objetividade necessária para tornar o processo factível dentro do tempo e dos recursos disponíveis, mesmo que para isso seja necessário simplificar processos, limitar a profundidade do estudo e 
relativizar a precisão e a abrangência dos resultados, preservando o que lhe é essencial: a contribuição para a tomada de decisão e para sua implementação (TANAKA; TAMAKI, 2012).

Este artigo objetiva discutir se o conjunto de intervenções, definidos na Norma de Atenção Humanizada ao Abortamento constitui um programa avaliável em uma maternidade-escola de referência do SUS em Natal, Rio Grande do Norte $(\mathrm{RN})$, Brasil. Tem a finalidade, ainda, de propor um modelo de avaliação da implantação desta norma, destacando seu modelo lógico, a matriz de indicadores e as perguntas avaliativas, bem como apresentar algumas recomendações para a pesquisa avaliativa subsequente.

O presente estudo contribuirá para subsidiar pesquisas e preencher uma das mais importantes lacunas existentes nos estudos sobre abortamento, que é a avaliação da implantação da Norma Técnica para Atenção Humanizada ao Abortamento.

\section{Metodologia}

O estudo de avaliabilidade correspondeu à apreciação da viabilidade e construção de um modelo avaliativo para Atenção Humanizada ao Abortamento em Hospital de Referência do SUS em Natal, Rio Grande do Norte. Foi realizado no período de agosto a novembro de 2011, seguindo a Resolução no 196/96 do Conselho Nacional de Saúde (CNS), que aprova as diretrizes e normas que regulamentam as pesquisas envolvendo seres humanos. $\mathrm{O}$ projeto de pesquisa foi previamente aprovado pelo Comitê de Ética em Pesquisa (CEP) da UFRN, sob parecer no 376/2009.

Para que um estudo de pré-avaliação seja realizado de forma adequada, é essencial seguir alguns critérios, como: delimitação do programa com a identificação de metas, objetivos e atividades; construção do modelo lógico considerando os recursos, atividades, impactos previstos e determinantes; a definição das perguntas avaliativas, bem como a escolha do desenho da avaliação e, por fim, as recomendações dos autores sobre o programa e a pertinência da realização da sua avaliação (THURSTON; RAMALIU, 2005).

Este estudo constou das seguintes etapas: construção do modelo lógico, matriz das dimensões de análise e relevância dos indicadores, formulação da das 
perguntas avaliativas, indicação do desenho da avaliação e recomendações para a realização da avaliação do programa.

\section{Modelo teórico lógico}

A construção do modelo lógico teve como propósito visualizar e sistematizar, com clareza, os pressupostos que norteiam o programa de Atenção Humanizada ao Abortamento. Na perspectiva apontada por Medina et al. (2005), o modelo deve conter o problema, objetivo geral, metas e objetivos específicos do programa. Apresenta seus componentes (palavras-chave retiradas dos objetivos específicos do programa), atividades (meios utilizados para atingir os resultados esperados), insumos (recursos físicos, materiais, financeiros e humanos necessários), produtos (consequências imediatas das atividades realizadas), resultados (mudanças que o programa pretende alcançar junto aos grupos para os quais está voltado) (HARTZ; VIEIRA-DA-SILVA, 1997).

Além disso, é importante que o modelo lógico seja revisado ao longo da intervenção e, caso tenha necessidade, seja readequado para captar novos aspectos não previstos no momento de sua elaboração inicial, a fim de que seja um instrumento de grande utilidade durante a realização da avaliação, uma vez que permite identificar as questôes nas quais devem se concentrar os esforços, dimensionando a capacidade de reorganização e resolutividade (SOUZA; VIEIRA-DA-SILVA; HARTZ, 2005).

Para a construção do modelo lógico, foram utilizadas as técnicas de análise documental e entrevista com informantes-chave. A análise documental sinaliza a construção de um discurso orgânico institucional e aponta para progressiva hegemonia de um dado discurso avaliativo, identificando áreas discursivas e práticas de diferenças e/ou resistências legítimas. Neste sentido, pode caracterizar paradoxos ou contradições, como a identificação de campos discursivos particulares, ao mesmo tempo em que ressalta o pluralismo e a multiplicidade de dimensões da análise (VASCONCELOS, 2002).

Nesta análise, utilizaram-se as seguintes bases de dados: Biblioteca Virtual em Saúde (BVS), PubMed, SciELO e sites governamentais. Foram incluídos apenas dois documentos técnicos institucionais, por orientarem, no período estudado, serviços seguros para o abortamento condizentes com os aspectos legais e éticos 
no Brasil: a Norma Técnica de Atenção Humanizada ao Abortamento, publicada pelo Ministério da Saúde em 2005, e "Abortamento seguro: orientação técnica e de políticas para os sistemas de saúde”, datada de 2004, pela Organização Mundial da Saúde. O primeiro permitiu o delineamento do programa e o segundo reafirmou a dimensão clínica da atenção. Excluíram-se documentos não-institucionais: cartas (02), notícias (02), outras orientações técnicas (02) e relatórios (02).

Para a entrevista, foram considerados informantes a diretora clínica, um médico docente e uma médica técnica e duas enfermeiras da referida maternidade. As entrevistas foram abertas, gravadas e realizadas no próprio hospital. Abordaramse os seguintes aspectos: existência do programa, através da implantação da norma, seus objetivos e ações desenvolvidas.

\section{Matriz de perguntas avaliativas}

Mediante pesquisa bibliográfica e elaboração do modelo lógico do programa, elaborou-se a matriz das perguntas avaliativas. Estas foram redimensionadas (fase convergente) para o foco da avaliação (implantação da atenção humanizada ao abortamento a partir daquelas mais amplas, inicialmente formuladas no projeto de pesquisa, que dizem respeito aos questionamentos e preocupaçóes mais amplas dos pesquisadores (fase divergente) (WORTHEN et al., 2004). Assim, conhecer o contexto da avaliação é essencial para atingir o seu objetivo, exigindo não apenas a identificação de perguntas e formulação de hipóteses, mas também a verificação do conjunto dos atores envolvidos, o grau de complexidade do problema e das ações a serem executadas e, especialmente, da concordância de perspectivas entre quem planeja e quem efetua a avaliação (MATIDA; CAMACHO, 2004).

Para garantir maior participação e viabilidade de execução, foram realizadas duas oficinas com o diretor clínico, profissionais médicos e enfermeiros. Foram explicados os objetivos da pesquisa e os possíveis indicadores, apresentadas sugestôes e pactuado o acesso às informaçôes, à entrada dos pesquisadores e à devolução processual dos resultados.

É importante ressaltar que a cooperação efetiva dos sujeitos envolvidos no processo de implantação de uma intervenção contribui, desde os primeiros achados do estudo, para que mudanças sejam promovidas visando à melhoria 
do programa. É ainda relevante ter a presença de um participante do programa envolvido como pesquisador, pois favorece a análise e interpretação dos dados no decorrer das etapas do estudo de avaliabilidade (THURSTON; RAMALIU, 2005; CARVALHO, 2008; SAMICO et al., 2010 ).

\section{Matriz de relevância dos indicadores}

Com base no modelo lógico, foi elaborada a matriz de relevância dos indicadores. Para validação, a matriz foi submetida ao julgamento de um grupo de nove especialistas, entre pesquisadores em avaliação de políticas e programas, médicos especialistas e docentes-pesquisadores da área da Saúde da Mulher.

Aplicou-se a técnica de consenso, denominada grupo nominal, com adaptação para a realização de três momentos presenciais distintos (POPE; MAYS, 2005). No primeiro momento, foram apresentados os objetivos da pesquisa e um painel com os indicadores. Em seguida, foi entregue uma planilha, contendo os critérios a serem atribuídos às notas. Após serem esclarecidas todas as dúvidas, cada especialista foi convidado a atribuir, de forma individual e anônima, notas de 0 a 10. Zero corresponderia à discordância completa, devendo o critério ser eliminado e 10 corresponderia à máxima concordância. Reservou-se também um espaço para comentários, caso a nota fosse zero, e para inclusão de novos critérios. Ao final, foram calculadas médias, para aferir a importância atribuída e desvios-padrão (DP), para verificar o grau de consenso entre as opiniōes dos especialistas sobre os critérios apresentados.

$\mathrm{Na}$ sequência, foram apresentados aos participantes reunidos as notas, médias e DP calculados e os novos critérios sugeridos, seguido de discussão. Após o debate, realizou-se nova roda de atribuição de notas. As respostas foram novamente consolidadas e calculadas médias e DP. Algumas sugestões, propostas no segundo momento, foram incorporadas aos critérios originais da matriz. Também ocorreram supressões, acréscimos ou complementação de critérios ou indicadores baseados nos argumentos das discussões e justificativas.

No terceiro momento, a matriz, proveniente da etapa anterior, foi repassada para nova planilha e os especialistas tiveram a oportunidade de manter ou mudar sua pontuação. Depois de recebidas as respostas, foram calculadas as médias e os DP da pontuação atribuída para a consolidação final e análise. 
Os indicadores foram analisados quanto à importância atribuída pelos especialistas, valendo-se da seguinte classificação da média de pontos obtidos: (a) média $<7$ = menor relevância (R); (b) média $\geq 7$ e $<9$ = média relevância (RR) (c) média $\geq 9$ =grande relevância (RRR). Quanto ao grau de consenso: (a) $\mathrm{DP} \leq 1=$ critério em consenso; (b) DP $>1$ e $<3$ = dissenso; (c) DP $\geq 3$ = grande dissenso. Aconselha-se submissão a comitê de especialistas, como um procedimento mais minucioso por autores como Souza, Silva e Hartz (2005) e Carvalho (2008).

\section{Resultados e discussão}

\section{$\mathrm{O}$ contexto da avaliação}

A maternidade-escola foi fundada nos anos de 1950, em Natal, Rio Grande do Norte. É um hospital de ensino público, desenvolvendo atividades acadêmicas e assistenciais. Em 2010, contava com 123 leitos e destes, 26 eram obstétricos cirúrgicos. Integra a rede municipal e estadual de serviços do SUS e é referência terciária para gestação de alto risco. Por estas características, oferta o atendimento às mulheres em situação de abortamento (espontâneo, induzido, voluntário ou terapêutico).

A proposta da maternidade de atender a todos os casos de demanda de abortamento, independentemente do fato de ser provocado ou não, aparece de forma explícita nas entrevistas. Há uma clara intenção dos médicos de procurar evitar constrangimentos às mulheres, a não ser que interfira na conduta, como nos casos de evidência de infecção. Entretanto, a grande demanda parece ser uma problemática para a realização adequada da prática do acolhimento, sendo este um dos principais pilares preconizados pela Norma Técnica para a Atenção Humanizada.

Todas que chegam são atendidas. É livre demanda. Desde o abortamento terapêutico, teve até um essa semana, até os casos de abortamento incompleto. Eu acho que é muito difícil, hoje, médico ficar perguntando a paciente se foi provocado, se não foi. Eu acho que a gente precisa respeitar a mulher. Então, se chegou com abortamento, eu não vou perguntar: tomou remédio? Não tomou? A não ser que seja um caso de abortamento com infecção. Aí, a gente precisa aprofundar mais a história. Mas se não for, a gente trata ela como abortamento e não entra no mérito (Diretora Clínica).

Elas, "coitadas", ficam esperando muito, mas porque a gente vai passando na frente mulher em trabalho de parto, as pacientes de risco, com choque ou alguma coisa assim, então elas ficam esperando. E nem sempre dá tempo fazer o acolhimento como deveria. (M2) 


\section{Modelo teórico lógico}

Um dos marcos para elaboração do modelo lógico é a Norma Técnica para Atenção Humanizada ao Abortamento, lançada em 2005. A norma tem como objetivos apoiar os profissionais e serviços de saúde e introduzir novas abordagens no acolhimento e na atenção. A meta é estabelecer e consolidar padrões culturais de atenção à saúde reprodutiva com base na necessidade das mulheres (BRASIL, 2005).

A Atenção Humanizada ao Abortamento propõe estratégias de expansão do acesso e melhoria da qualidade da atenção ao pós-abortamento. O marco conceitual é composto por cinco elementos essenciais: atenção clínica adequada a padrōes éticos e legais, visando promover maior conhecimento pelos profissionais de saúde das questões jurídicas relacionadas ao abortamento no Brasil, acolhimento e informação como elemento essencial para uma atenção humanizada ao pósabortamento, por responder às necessidades da mulher, seja ela de caráter emocional, social ou física; prática integrada com as outras clínicas de atenção à saúde da mulher, como tratamento de esterilidade, atenção às adolescentes, prevenção de HIV/Aids, dentre outros; garantia do planejamento reprodutivo no pós-abortamento, parceria entre comunidade e profissionais de saúde, a fim de contribuir para mobilizar recursos, de forma a prevenir gestações indesejadas e atender às necessidades da população feminina adstritas aos serviços de saúde. Neste sentido, norteiam a humanização e a qualidade da atenção prestadas que podem servir de marco para sua avaliação.

Em 2010, o Ministério da Saúde apresentou aos profissionais uma nova edição com revisão da Norma Técnica, reafirmando as orientações gerais de acolhimento, orientação e atenção clínica dentro da Política Nacional à Saúde da Mulher na perspectiva de açôes intra e intersetorial, que fazem parte do Pacto Nacional pela Redução da Mortalidade Materna e Neonatal. Também está caracterizada como resultante da atuação articulada entre o Ministério da Saúde e a Secretaria Especial de Políticas para as Mulheres (SPM) (BRASIL, 2010). O modelo lógico está descrito na figura 1 : 


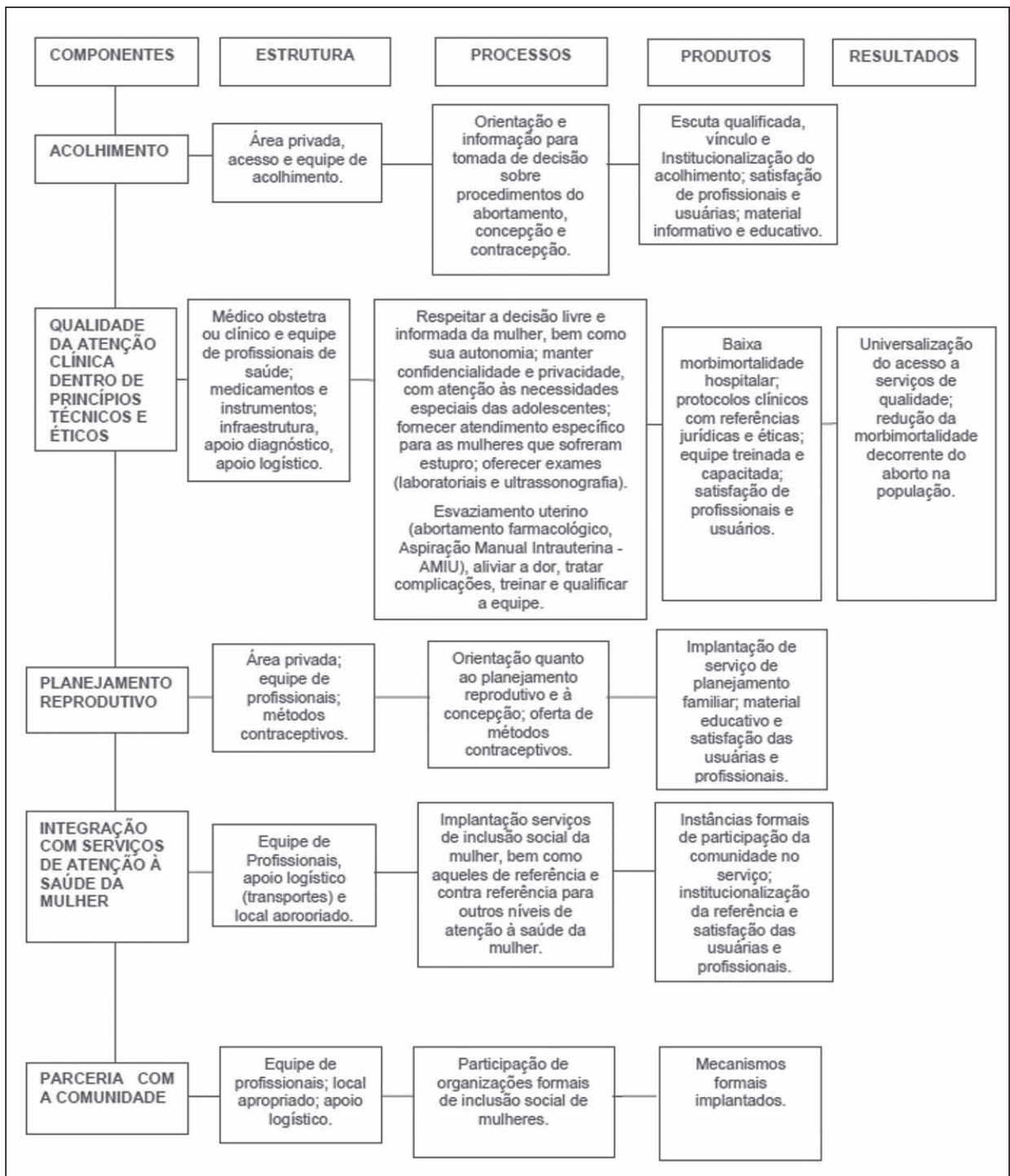

\section{Matriz de indicadores}

Com as bases do modelo lógico, foram descritas as seguintes dimensōes de qualidade, de modo a contemplar os diferentes componentes do programa, a ser avaliado, além dos indicadores e categorias que apontam para diferentes técnicas de investigação. Esta matriz pode ser vista no quadro 1. 

coleta e fontes de informação.

\begin{tabular}{|c|c|c|}
\hline $\begin{array}{l}\text { DIMENSÃO DE } \\
\text { ANÁLISE }\end{array}$ & INDICADORES/CATEGORIA & $\begin{array}{l}\text { TÉCNICAS DE COLETA E } \\
\text { FONTES DE INFORMAÇÃO }\end{array}$ \\
\hline $\begin{array}{l}\text { Político- } \\
\text { Institucional e } \\
\text { ética }\end{array}$ & $\begin{array}{l}\text { Antecedentes } \\
\text { Diferentes contextos políticos, jurídicos e éticos } \\
\text { nacionais e internacionais de serviços seguros de } \\
\text { abortamento; }\end{array}$ & $\begin{array}{l}\text { Análise documental e Revisão } \\
\text { Sistemática }\end{array}$ \\
\hline \multirow{4}{*}{ Acolhimento } & Acesso & Entrevista com profissionais e usuárias \\
\hline & $\begin{array}{l}\text { Escuta qualificada, vínculo e Institucionalização do } \\
\text { acolhimento; }\end{array}$ & \\
\hline & $\begin{array}{l}\text { Orientação e informação para tomada de decisão } \\
\text { sobre procedimentos do abortamento, concepção e } \\
\text { contracepção; }\end{array}$ & \\
\hline & Satisfação de usuárias e profissionais; & \\
\hline \multirow{10}{*}{$\begin{array}{l}\text { Integralidade da } \\
\text { Atenção }\end{array}$} & $\begin{array}{c}\text {-Referenciais jurídicos, éticos e bioéticos na } \\
\text { atenção. }\end{array}$ & $\begin{array}{c}\text { Entrevista com Gestores e profissionais } \\
\text { Análise documental; } \\
\text { Diário de campo }\end{array}$ \\
\hline & $\begin{array}{l}\text {-Atenção às necessidades especiais das adolescentes; } \\
\text { e atendimento específico para as mulheres que } \\
\text { sofreram estupro. }\end{array}$ & Entrevista com Gestores e profissionais \\
\hline & -Concepções sobre aborto & \\
\hline & $\begin{array}{l}\text {-Protocolos e realização: exames (laboratoriais, } \\
\text { ultrassonografia, entre outros); Esvaziamento } \\
\text { uterino (abortamento farmacológico, Aspiração } \\
\text { manual intrauterina- AMIU); Alívio da dor; } \\
\text { Tratamento das complicaçôes; }\end{array}$ & Entrevista com profissionais e usuárias \\
\hline & Morbimortalidade hospitalar & \\
\hline & Treinamento e qualificação da equipe. & Análise documental \\
\hline & Trabalho em equipe & Entrevista com profissionais e usuárias \\
\hline & Motivação para o atendimento & \\
\hline & Satisfação de usuárias e profissionais; & \\
\hline & Infraestrutura & Observação com roteiro \\
\hline \multirow{4}{*}{$\begin{array}{l}\text { Planejamento } \\
\text { reprodutivo }\end{array}$} & $\begin{array}{l}\text { Orientação em planejamento reprodutivo e } \\
\text { concepção }\end{array}$ & $\begin{array}{l}\text { Diário de campo } \\
\text { Entrevista com profissionais e usuárias }\end{array}$ \\
\hline & Oferta de métodos contraceptivos & \\
\hline & Institucionalização do planejamento & \\
\hline & Satisfação de usuárias e profissionais & \\
\hline
\end{tabular}




\begin{tabular}{|l|c|c|}
\hline \multirow{2}{*}{$\begin{array}{l}\text { Integração com } \\
\text { serviços de } \\
\text { atenção à saúde } \\
\text { da mulher }\end{array}$} & $\begin{array}{c}\text { Implantação de serviços de referência e contra } \\
\text { referência para outros níveis de atenção. }\end{array}$ & Entrevista com profissionais e usuárias \\
\cline { 2 - 3 } & Institucionalização da referência & \\
\cline { 2 - 3 } & Satisfação de usuárias e profissionais & \\
\hline $\begin{array}{l}\text { Parceria com a } \\
\text { comunidade }\end{array}$ & $\begin{array}{c}\text { Participação de organizações de inclusão social de } \\
\text { mulheres }\end{array}$ & Entrevista com profissionais e usuárias \\
\hline
\end{tabular}

\section{A implantação da norma, seus objetivos como condição para avaliação}

De acordo com a diretoria clínica do hospital estudado, a Norma de Atenção Humanizada ao Abortamento foi implantada em 2005, havendo um momento inicial de capacitação dos profissionais. Entretanto, a fala a seguir evidencia constrangimentos pela alta demanda que impóe um atendimento emergencial, que ultrapassa a capacidade de resposta do serviço dentro de padrôes normatizados:

A gente já passou da fase de discutir sobre a norma técnica. A gente já fez muita capacitação sobre isso daí. Então, os profissionais que, hoje, estão no plantão, que somos 22 médicos, as enfermeiras (praticamente todas elas), a gente já foi capacitado algumas vezes sobre isso daí, entendeu? O problema da atenção é pela superlotação que, muitas vezes, a gente não consegue... Então, a norma é implementada quando pode. Eu acho que ela é parcialmente implementada, é quando dá , quando pode, quando eu tenho tempo e não tem outras urgências na frente, eu consigo fazer isso daí, mas... às vezes, não (Diretora Clínica).

Não apenas para a direção clínica, mas também para os profissionais, a questão da implantação da norma não era algo estranho a sua prática, justificando a possibilidade de avaliação :

Tem um acolhimento, tem uma atenção... já faz um certo tempo que a gente trabalha com uma atenção humanizada para o abortamento. Ela passa por três salas: a sala de espera, a sala de expectação e o centro cirúrgico (Médico 2).

Pelo depoimento dos profissionais, ocorreram algumas mudanças estruturais, no sentido de adaptar aos padrões de qualidade exigidos. Estas não eram circunscritas à atenção ao abortamento, mas reforçava a capacitação específica. Entretanto, são levantadas referências relativas à descontinuidade da norma:

$\mathrm{Na}$ época que passaram esse programa, ele foi operacionalizado e aconteceu, só que devido às mudanças [...] aqui, reformas [...] juntaram setores, aumentaram outros, a central de material que a gente tinha e era pequenininha agora está maior, está dentro dos padrōes da ANVISA. O centro cirúrgico do primeiro andar, que a COVISA 
estava em cima, foi ampliado. Então, tomou espaço e diminuiu o espaço que a gente

tinha para setores. Aí, eu penso que, quando "isso" retornar, deve ser feito novamente, como foi feito anteriormente... Faz uns três a quatro anos que a norma foi discutida e, na época, foi feita reunião e treinamento com o pessoal. Até que ela foi muito utilizada, quando foi pra introduzir a AMIU. Então, foi feito todo um treinamento, inclusive esse curso de AMIU, ficou sendo dado a todo grupo que chegava. Agora, quem faz o procedimento é o médico, mas os enfermeiros, também, eram convidados para participarem, para compreenderem e até a questão da manutenção do próprio material (Enfermeiro 2).

Nós já tivemos treinamento e já fomos informados dessa Norma Técnica, justamente quando nós implantamos, implementamos. Mas não é coisa recente, que estejamos fazendo recentemente, nem vamos dizer que tem educação continuada a respeito, mas existe a sensibilização. Ela foi implantada, mas sua implementação deixa a desejar (Médica 3).

\section{Perguntas avaliativas}

Com base no modelo lógico, matriz dos indicadores e nas entrevistas, foram elaboradas as seguintes perguntas avaliativas: "Qual o contexto político, jurídico, ético e bioético que condiciona a implantação do programa de Atenção Humanizada ao Abortamento no SUS do Rio Grande do Norte?" e "Os processos (acolhimento, atenção, planejamento, parceria com a comunidade) e os resultados encontrados apontam para qualidade da atenção?”

Afirmam Tanaka e Tamaki (2012) que sem uma clara pergunta avaliativa, como ponto de partida, não se consegue produzir uma avaliação e sim um diagnóstico. E reforçam que a ausência de clareza na formulação da pergunta acarretará no acúmulo de dados e de informações que poderão não ser úteis na tomada de decisão para alterar determinada situação de saúde da população.

\section{Considerações finais e recomendações}

O programa de Atenção Humanizada ao Abortamento é considerado avaliável, pois apresenta definição clara e coerente de suas metas, objetivos, operacionalização e recursos.

O estudo de avaliabilidade foi adequado ao evidenciar a pertinência entre normatividade, resultados e metas, potencializando a mobilização interna e externa indispensáveis ao alcance das mudanças do padrão cultural pretendido. As oficinas para elaboração e pactuação do modelo lógico, formulação de perguntas avaliativas e validação da matriz de indicadores possibilitaram ampla 
discussão entre profissionais e gestores sobre objetivos, metas, sensibilidade indicadores, aumentando o conhecimento de todos os envolvidos. Trouxeram ao cotidiano do serviço a discussão sobre humanização que apresentava momentos de avanços e retrocessos. O papel da direção clínica foi decisivo neste acúmulo e na disponibilização das informaçooes e interação dos profissionais na avaliação.

$\mathrm{Na}$ confrontação do modelo lógico com a realidade durante as entrevistas e observações locais, perceberam-se dificuldades na operacionalização das dimensões de acolhimento, atribuídas especialmente a grande demanda e falta de articulação com uma rede de cuidados entre os serviços do SUS.

O estudo permitiu ainda elaborar as perguntas avaliativas que envolvem a visão ampliada do contexto político, jurídico, ético e bioético e dos processos constituintes da política de atenção humanizada ao abortamento que permitirão estruturar um efetivo protocolo de avaliação. Assim, as questões elaboradas permeiam pontos estratégicos da política que irão colaborar no direcionamento da intervenção e permitir uma reflexão sobre os limites e possibilidades da avaliação.

O momento é bastante oportuno a uma subsequente avaliação somativa, considerando os oito anos de implantação da norma, sua reedição e os resultados do estudo de avaliabilidade. Recomenda-se que a mesma integre os cinco componentes que são imprescindíveis ao sucesso do programa. Para os envolvidos, esta avaliação deverá priorizar tanto os aspectos subjetivos da humanização, particularmente o acolhimento, quanto a estrutura. Este enfoque contribuirá como subsídio para melhoria destas dimensões ainda frágeis do programa. A magnitude do abortamento tem influência direta na qualidade de ambas, devendo ser dimensionada. O estudo de caso para avaliação da qualidade nas dimensões de processos e estrutura, suplementado com o estudo de prevalência, apresenta-se como opção metodológica adequada.

O protocolo de avaliação resultante poderá ser adaptado e pactuado como ferramenta de planejamento, gestão e autoavaliação, o que favorecerá a institucionalização da avaliação. Ainda que não se avalie impacto, a ênfase na avaliação de estrutura e processo poderá subsidiar a decisão dos gestores na área de saúde da mulher dos diferentes níveis (serviços, municipais, estaduais) e as práticas dos profissionais. Tais contribuições poderão reforçar ou corrigir "rotas", mesmo antes do desfecho (impacto) desfavorável por abortamento inseguro. ${ }^{1}$ 


\section{Referências}

ADESSE, L,; MONTEIRO, M.F.G; LEVIN, J. Grave problema de saúde pública e de justiça social. Radis - Comunicação em Saúde, n.66,p.10-15, fev. 2008.

BENUTE, G.R.G. et al. Influência da percepção dos profissionais quanto ao aborto provocado na atenção à saúde da mulher. Rev. Bras. Ginecol. Obstet. Rio de Janeiro, v.34, n.2, p. 69-73, fev. 2012.

BRASIL. Ministério da Saúde Sistema de Informações Hospitalares do SUS (SIH/SUS). Disponível em: <www.datasus.gov.br>. Acesso em: 30 jun 2012.

BRASIL. Ministério da Saúde. Secretaria de Atenção à Saúde. Departamento de Ações Programáticas Estratégicas. Área Técnica de Saúde da Mulher. Atenção humanizada ao abortamento: norma técnica. Brasília, 2005. 36p. (Série Direitos Sexuais e Direitos Reprodutivos-Caderno 4).

BRASIL. Ministério da Saúde. Secretaria de Atenção à Saúde. Departamento de Ações Programáticas Estratégicas. Atenção Humanizada ao Abortamento: Norma Técnica. 2. ed. atual. e ampl. Brasília:MS, 2010.

BRASIL. Superior Tribunal Federal. Arguição de Descumprimento de Preceito Fundamental no 54. Relator: Marco Aurélio Mello. Plenário. Diário Oficial da União, Brasília, DF, Seção 1, p. 1, 24 abril 2012.

DINIZ, D.; MEDEIROS, M. Aborto no Brasil: uma pesquisa domiciliar com técnica de urna. Ciênc. saúde coletiva. Rio de Janeiro, v.15, supl.1, p.959-66, jun. 2010

GRIMES, A. et al. Unsafe abortion: the preventable pandemic. The Lancet, 1, p. 1-12, nov. 2006.

HARTZ, Z.M.de A.; VIEIRA-DA-SILVA, L.M. (Org.). Avaliação em saúde: dos modelos conceituais à prática na análise da implantação de programas. Rio de Janeiro: Fiocruz, 1997. MEDEIROS, R.D. et al. Opinião de estudantes dos cursos de Direito e Medicina da Universidade Federal do Rio Grande do Norte sobre o aborto no Brasil. Rev. Bras. Ginecol. Obstet. Rio de Janeiro, v.34, n.1, jan. 2012.

MEDINA, F.G. et al. Uso de modelos teóricos na avaliação em saúde: aspectos conceituais e operacionais. In: HARTZ, Z.M. de A.; VIEIRA-DA-SILVA L.M. (Org.). Avaliação em saúde: dos modelos teóricos à prática na avaliação de programas e sistemas de saúde. Salvador: EDUFBA, 2005.

MENEZES, G.; AQUINO, E.M.L. Pesquisa sobre o aborto no Brasil: avanços e desafios para o campo da saúde coletiva. Cad Saúde Pública. Rio de Janeiro, v.25, supl. 2, p.193-S204, 2009. MOTTA, I.S. da. A relação interpessoal entre profissionais de saúde e a mulher em abortamento incompleto: "o olhar da mulher". Rev. Bras. Saude Mater. Infant. Recife, v.5, n.2, jun. 2005. 
OPALEYE, E.A. et al. Avaliação de riscos teratogênicos em gestações expostas ao misoprostol. Rev. Bras. Ginecol. Obstet., v.32, n.1, p.19-35, 2010.

ORGANIZAÇÃO PANAMERICANA DA SAÚDE. Profissionais capacitados para combater mortalidade materna. 2005. Disponível em <http://66.102.7.104/ custom?q=cache:ftARtegE1jkJ:www.opas.org.br/rh/noticia_det.cfm\% 3Fid_noticia\%3D224+ mortalidade + materna\&hl=pt-BR\&ie=iso-8859-1>. Acesso em: 12 ago. 2012.

ORGANIZAÇĀO MUNDIAL DA SAÚDE. International Women's Health Coalition. Abortamento Seguro: orientação técnica e politica para os sistemas da saúde. Campinas: Cemicamp; 2004. Disponível em : http://www.iwhc.org/index.php?option=com_conten t\&task=view\&id=3072\&Itemid=751. Acesso em: 05 set. 2012.

OSIS, M.J.M.D. PAISM: um marco na abordagem da saúde reprodutiva no Brasil. Caderno de Saúde Pública. Rio de Janeiro, v.14, supl.1, p.25-32, 1998.

POPE, C.; MAYS, N. (Orgs.). Pesquisa qualitativa na atenção à saúde. 2.ed. Porto Alegre: Artmed, 2005. p.71-86.

SANTOS-FILHO, S.B. Perspectivas da avaliação na Política Nacional de Humanização em Saúde: aspectos conceituais e metodológicos. Ciência Saúde Coletiva. Rio de Janeiro, v.12, n.4, p.999-1010, 2007.

TANAKA, O.Y.; TAMAKI, E.M. O papel da avaliação para a tomada de decisão na gestão de serviços de saúde. Ciência Saúde Coletiva. Rio de Janeiro, v.17, n.4, p.821-828, 2012.

THURSTON, W.E.; RAMALIU, A. Avaliação da avaliabilidade de um programa para sobreviventes de tortura: lições aprendidas. The Canadian Journal of Program Evaluation, v.20, n.2, p.1-25, 2005.

TREVISAN, M.S.; HUANG, Y.M. Evaluability assessment: a primer. Practical Assessment, Research \& evaluation, v.8, n.20. Disponível em: <http://www.pareonline.net>. Acesso em: 10 nov. 2012.

VASCONCELOS, E.M. Complexidade e pesquisa interdisciplinar: epistemologia e metodologia operativa. Petrópolis: Vozes, 2002.

WORTHEN, B.R.; SANDERS, J.R.; FITZPATRICK, J.L. Avaliação de programas: concepções e práticas. São Paulo: Gente, 2004.

\section{Nota}

${ }^{1}$ B.N.G.A. Rocha e S.A.C. Uchoa participaram igualmente da concepção, análise, interpretação dos dados, revisão crítica e redação final do texto. 


\section{Abstract}

Evaluation of humanized care in abortion: an evaluability study

In Brazil, it is estimated that 1,443,350 abortions occur annually, leading thousands of women with incomplete abortion, to seek care in public health. In 2005, the Ministry of Health published the Technical Act for Humane Abortion in response to this challenge. This paper discusses whether the Act sets an evaluable program and proposes an evaluation model. The survey, conducted in 2010, is an evaluability study using techniques of document analysis and interviews with key informants. To validate the indicators, we applied the nominal group technique. The results were elaborated and agreed upon the logical model, the matrix of indicators and evaluative questions that reflect the pillars of care: care, quality clinical care with technical, ethical and legal, reproductive planning, integration with network health and collective women. We conclude that the humanized abortion is an assessable program with development of an evaluation model in a timely manner. The preassessment was suitable and better understood by managers and professionals. There was agreement about the explicitness and relevance of goals, actions, and resource needs, ethical questions to guide changes. The study has increased the knowledge of the actors involved with decisive participation of clinical direction. For subsequent evaluations, the study recommends focusing on the structure and processes of the five components of the program with prioritization of subjective aspects of humanization, infrastructure, and the prevalence of abortion in the public health service.

Key words: evaluation; abortion; humanization; women's health. 